\title{
JUVENTUDE RURAL E NOVAS FORMAS DE SOCIABILIDADE MEDIADAS PELAS TICS
}

\author{
Rural youth and new forms of sociability mediated by tics
}

\section{Juventud rural y nuevas formas de sociabilidad mediadas por las tics}

\author{
Ezequiel Redin ${ }^{1}$ \\ Paulo Roberto Cardoso da Silveira ${ }^{2}$ \\ Gisele Martins Guimarães ${ }^{3}$ \\ Vilson Flores dos Santos ${ }^{4}$
}

\section{Resumo}

Com base na experiência de organização dos jovens rurais da Região Centro Serra do Rio Grande do Sul-Brasil, a qual envolve em torno de 9.000 jovens de 12 municípios, este trabalho propõe-se a analisar as mudanças nas formas de sociabilidade vivenciadas em um processo de transformação da vida rural provocado pela universalização do uso das TICs. Neste esforço investigativo, busca-se analisar o impacto nas relações sociais locais e sobre a projeção futura da vida dos jovens no espaço rural. Deste modo, percebem-se as transformações na perspectiva da juventude rural como ator coletivo, as quais redefinem o

\footnotetext{
${ }^{1}$ Tecnólogo em Agropecuária: Sistemas de Produção (UERGS) CREA RS 160488; Bacharel em Administração (ULBRA); Especialista em Gestão Pública Municipal (UFSM); Mestre e Doutorando em Extensão Rural (UFSM); Editor do Periódico Extensão Rural (Santa Maria) http://cascavel.ufsm.br/revistas/ojs2.2.2/index.php/extensaorural/index - Revisor de 22 periódicos nacionais; Membro da Academia Centro Serra de Letras; Membro da Rede Temática de Diversificação em Áreas Cultivadas com Tabaco, organizada pelo Ministério do Desenvolvimento Agrário (MDA). Tesoureiro da Associação Rio-grandense dos Tecnólogos (ARTECNOL). CV: http://lattes.cnpq.br/4594328596786231

${ }^{2}$ Possui graduação em Zootecnia pela Universidade Federal de Santa Maria (1989), mestrado em Extensão Rural pela Universidade Federal de Santa Maria (1994) e doutorado pelo Programa Interdisciplinar em Ciências Humanas da Universidade Federal de Santa Catarina (2010). Atualmente é professor da Universidade Federal de Santa Maria. E-mail: prcs1064@yahoo.com.br

${ }^{3}$ Possui graduação em Zootecnia pela Universidade Federal de Santa Maria (UFSM), Mestre em Extensão Rural pela mesma instituição e Doutora em Desenvolvimento Rural (PGDR), pela Universidade Federal do Rio Grande do Sul - UFRGS. É Professora Adjunta na Universidade Estadual do Rio Grande do Sul - UERGS, lotada na Unidade em Cachoeira do Sul, onde exerce o cargo de Coordenadora do Curso Superior Tecnológico em Agropecuária Integrada e membro no Conselho Superior da UERGS - CONSUN. Email: giseleguima@yahoo.com.br

${ }^{4}$ Licenciado em Estudos Sociais pela Faculdade de Filosofia Ciências e Letras de Santiago (1982), Graduado em Disciplinas Especializadas do Ensino de $2^{\circ}$ Grau - Área Econômica Primária, pela Universidade Federal de Santa Maria (1992) e Mestrado em Extensão Rural pela Universidade Federal de Santa Maria (2004). Email: vilsonflores@yahoo.com.br
} 
Juventude rural e novas formas de sociabilidade mediadas pelas tics

de Ezequiel Redin, Paulo Roberto Cardoso da Silveira, Gisele Martins Guimarães e Vilson

Flores dos Santos

sentido atribuído ao rural e impactam no processo de construção identitária, propondo uma reflexão sobre as motivações e tensões vivenciadas.

Palavras- chave: juventude rural, TICs, sociabilidade, agricultura familiar.

\begin{abstract}
Based on the experience of organization of rural youth in the Central Sierra of Rio Grande do Sul, Brazil, which involves around 9,000 young people from 12 counties, this study aims to examine the changes in the forms of sociability experienced in a process transformation of rural life caused by the universal use of ICTs. In this investigative effort, seeks to analyze the impact on local social relations and the future projection of the lives of young people in rural areas. Thus, we can see the changes in the perspective of rural youth as a collective actor, which redefines the meaning assigned to rural and impact on identity construction process, proposing a reflection on the motivations and tensions experienced.
\end{abstract}

Keywords: rural youth, ICT, sociability, family farming.

\title{
Resumen
}

Con base en la experiencia de la organización de la juventud rural en la Región Central de Serra do Rio Grande do Sul , Brasil, que involucra alrededor de 9.000 jóvenes en 12 condados, este estudio tiene como objetivo examinar los cambios en las formas de sociabilidad que experimentan en un proceso transformación de la vida rural causado por el uso universal de las TICs. Este esfuerzo de investigación, busca analizar el impacto en las relaciones sociales locales y la proyección futura de las vidas de los jóvenes de las zonas rurales. Por lo tanto, las transformaciones se perciben desde la perspectiva de la juventud rural como actor colectivo, que redefine el significado dado a las zonas rurales y el impacto sobre el proceso de construcción de la identidad, que propone una reflexión sobre las motivaciones y las tensiones experimentadas .

Palabras-clave: juventud rural, las TIC, la sociabilidad, la agricultura familiar.

\section{INTRODUÇÃO}

Nos últimos quarenta anos, percebe-se uma mudança significativa no mundo rural. A partir da década de 1990, a literatura tem documentado elementos desta mudança, seja a 
Juventude rural e novas formas de sociabilidade mediadas pelas tics

de Ezequiel Redin, Paulo Roberto Cardoso da Silveira, Gisele Martins Guimarães e Vilson

Flores dos Santos

redução do número de famílias envolvidas com a agricultura e a emergência de atividades não-agrícolas no espaço rural, seja a presença da agricultura de tempo parcial e da pluriatividade como novas características da organização do trabalho nas famílias rurais. Neste "novo rural", atividades como turismo, indústria, comércio e serviços surgem com crescente importância na ocupação da força de trabalho disponível (GRAZIANO DA SILVA, 1999), enquanto o intenso êxodo provoca um envelhecimento da população do campo e uma constatada masculinização entre os remanescentes (CAMARANO e ABRAMOVAY, 1999).

Neste processo de transformação do rural, assume relevância a dimensão demográfica, a qual tem sido acompanhada por dois processos simultâneos e imbricados que transformaram significativamente o espaço rural: a sua crescente urbanização e a migração dos jovens em direção às cidades.

Pode-se caracterizar a urbanização do rural como um processo alicerçado nas transformações das condições de transporte e comunicação, as quais rompem com o isolamento que tradicionalmente assolava as comunidades do campo. Estas novas possibilidades aproximam o rural do urbano, facilitando o acesso da sociedade rural aos produtos e serviços ofertados na cidade, enquanto melhoram significativamente a infraestrutura (energia elétrica, redes de abastecimento de água, telefonia, condições viárias) e os serviços públicos (saúde, educação) disponíveis no campo. Se somarmos a este processo a aglutinação da população em pequenas vilas e redutos urbanos, recentemente emancipados politicamente, temos um contexto em que muda significativamente o modo de vida rural.

Os estudos recentes sobre o desenvolvimento rural no Brasil tendem a enfatizar a intensa migração dos jovens rurais, os quais tem abandonado o campo em busca de opções de estudo ou emprego com salário fixo e com os direitos de previdência social respeitados. Este êxodo dos jovens provoca uma ameaça a sucessão familiar, o que implica questionar-se sobre um provável esvaziamento do rural em um futuro próximo. Ao examinar este processo no qual a juventude rural assume a perspectiva de não permanecer no campo, as pesquisas apontam diversas motivações para este comportamento, da baixa expectativa de renda na agricultura camponesa, a falta de participação na gestão da economia familiar e a busca por melhor infraestrutura, serviços públicos e opções de lazer (REDIN e SILVEIRA, 2012). No entanto, estes autores advertem que para reverter esta tendência, além destes fatores que estimulam a saída do rural, torna-se necessário refletir sobre os aspectos que os estimulam a permanecer, pesando nas decisões da juventude rural. 
Juventude rural e novas formas de sociabilidade mediadas pelas tics

de Ezequiel Redin, Paulo Roberto Cardoso da Silveira, Gisele Martins Guimarães e Vilson

Flores dos Santos

Torna-se fundamental na construção deste artigo, enfatizar a compreensão do conceito de Juventude Rural, o qual assume significado de um ator coletivo, relacionado a um projeto identitário que implica na dimensão da organização e luta política. Deste modo, ultrapassa-se o enfoque que ressalta apenas fatores de ordem individual, a qual tem como consequência uma análise que particulariza a situação de cada família e não enfatiza os elementos relativos às expectativas e perspectivas dos jovens enquanto grupo social, os quais agem e re-agem condicionados pelas políticas públicas que interferem nas condições estruturais e conjunturais presentes em cada território (REDIN e SILVEIRA, 2012).

Assim, observam-se na sociedade rural dois tipos de processos de sociabilidade: aquelas que afetam toda a população rural e em específico os jovens rurais enquanto sujeitos individuais que se relacionam no cotidiano local e sua relação com a sociedade globalizada; e uma outra sociabilidade que se expressa no agir coletivo marcado pela constituição das associações de jovens rurais em cada município da região em análise e congregadas na Associação Regional da Juventude Rural, a AREJUR, onde define-se um outro âmbito de relações sociais e políticas, articuladas com o processo identitário em construção e que permite falarmos em Juventude Rural.

Neste artigo, busca-se enfatizar as contemporâneas formas de sociabilidade possibilitadas pelas novas tecnologias de informação e comunicação (TICs), as quais interferem decisivamente no modo de vida rural, criando possibilidades de interação com a sociedade global e expectativas para os jovens rurais em relação a sua trajetória de vida e em afinidade a sua participação no movimento da Juventude Rural. Este processo também implica em novas perspectivas para este segmento da população rural, seja nos aspectos de acesso à informação como nas novas possibilidades de interação social. Ao mesmo tempo, observa-se um menor apego as antigas formas de sociabilidade, caracterizadas pelas festas locais, eventos esportivos ou cerimônias religiosas. Neste cenário, abordamos a relação entre estas novas sociabilidades e o processo organizativo da juventude rural, analisando o impacto nas expectativas e perspectivas dos jovens rurais, ao mesmo tempo em que se aponta a intensidade do declínio das "velhas" formas de sociabilidade vivenciadas no rural.

Para tanto, toma-se como base a experiência de organização dos jovens rurais da Região Centro Serra do Rio Grande do Sul, reunidos e organizados pela AREJUR, a qual envolve em torno de 9.000 jovens de 12 municípios da Região Centro Serra, Rio Grande do Sul. Justifica-se este recorte, pois esta experiência permite compreender como as TICs podem 
Juventude rural e novas formas de sociabilidade mediadas pelas tics

de Ezequiel Redin, Paulo Roberto Cardoso da Silveira, Gisele Martins Guimarães e Vilson

Flores dos Santos

impactar na ação coletiva e na criação de novas sociabilidades para os rurais. Ainda, deve-se destacar que as análises sobre a juventude rural no estado têm constatado, conforme Weisheimer (2009: 307), que "a situação juvenil na agricultura familiar se caracteriza ainda por um baixo acesso às atividades de lazer" e as TICs representam novas possibilidades de sociabilidade, permitindo que os jovens rurais conectem-se com a sociedade globalizada, redimensionando suas relações sociais e redefinindo as bases de seu processo identitário.

\section{JUVENTUDE RURAL E AS TICS - APROXIMAÇÕES METODOLÓGICAS}

A juventude rural contemporânea está imersa num conjunto de novas relações de sociabilidade que constituem e se reconstituem diante das Tecnologias de Informação e Comunicação (TICs) presentes no rural brasileiro. Estas, por sua vez, correspondem a todas as tecnologias que interferem e mediam os processos informacionais e comunicativos.

As TICs constituem um conjunto de recursos tecnológicos integrados entre si, que proporcionam, por meio das funções de hardware, software e telecomunicações, interações entre processos de negócios, de pesquisa científica, de ensino e aprendizagem. Como exemplo citamos o rádio, o telefone (fixo e móvel) a televisão (analógica e digital) e a internet, considerada a responsável pela revolução das redes em função de sua capacidade de promover interatividade entre os sujeitos, aproximando sentidos através da informação e mecanismos de sociabilidade, como o fazem as redes sociais.

Neste sentido, considera-se que estas têm papel fundamental no desenvolvimento uma vez que facilitam o processo de comunicação, compreendido, em sua essência, como capital social para os atores que necessitam dela para tomar suas decisões de produção e convivência (BORDENAVE, 1983).

Vale lembrar que o processo de comunicação no meio rural sempre esteve ligado a informação, esta sob uma perspectiva técnica, tecnológica ou ainda de lazer como faziam e ainda o fazem os inúmeros programas de rádio que atingem o meio rural por meio das músicas e informes técnicos. No entanto salienta-se que sob esta perspectiva, a informação não é reconhecida como comunicação pela passividade com que os sujeitos a recebem. Completando essa análise nos reportamos a Paulo Freire (1977) que assinala a importância da reciprocidade que não pode ser rompida para que haja o ato comunicativo, o que implica em uma relação dialógica e não unidirecional. 
Juventude rural e novas formas de sociabilidade mediadas pelas tics

de Ezequiel Redin, Paulo Roberto Cardoso da Silveira, Gisele Martins Guimarães e Vilson

Flores dos Santos

De outro lado, considerando-se a revolução da comunicação por meio da internet, percebe-se a possibilidade de interatividade entre os sujeitos, esta dada pela troca em duas ou mais vias de diálogo. Este fenômeno de reciprocidade seria então capaz de promover comunicação, ou seja, se daria por meio de relações e significações sociais construídas de forma coletiva pelas partes envolvidas: emissores e receptores, tendo a máquina como meio de mediação.

E é deste mecanismo de construção em rede, proporcionado pela internet, que surgem as possibilidades de sociabilidade, termo este sugerido por Georg Simmel (1983) que implica em interação entre os sujeitos. Esta, movida na sociedade por objetivos comuns partilhados, como posição social, cultura, fama e aumento de capacidades por meio da informação e formação. Todas estas e outras questões favorecidas pelo acesso crescente dos atores às Tecnologias da Informação e Comunicação, cada vez mais presente entre os jovens, tanto urbanos quanto rurais, muito embora os últimos ainda estejam em evidente desvantagem quando comparados aos primeiros, no acesso ao serviço, como demonstram os dados de pesquisa do Comitê Gestor da internet no Brasil, indicando que presença do computador na área urbana atinge $51 \%$ dos estabelecimentos, enquanto na área rural chegam a $16 \%$ nos domicílios (CGI, 2012).

No entanto, é fundamental que se reconheça que as TICs no meio rural potencializam a comunicação e facilitam as trocas, de experiências, sobretudo, entre os jovens, que veem nela a possibilidade de sair para além de seus espaços geográfico e social, podendo fazer-se pertencer a diferentes redes, onde a organização social pode emergir como resultado de um processo de partilha de interesses e sentimentos de pertencimento.

No recorte empírico deste estudo (Região Centro Serra do RS/Brasil), encontram-se disseminados, em ordem cronológica, o rádio, a televisão, telefone fixo, o celular, computador e internet, por último, mais contemporâneo os smartphones.

Para fins metodológicos, este trabalho realiza um recorte em relação ao computador e a internet, que cada vez mais fazem parte do cotidiano dos rurais. No primeiro momento influenciam nos trabalhos escolares estendendo-se aos momentos de lazer, num segundo momento, significam um potencial de mudança na sociabilidade, antes dependentes das festas locais e hoje fundadas também na aproximação com jovens urbanos (fisicamente ou virtualmente) através das redes sociais. 
Juventude rural e novas formas de sociabilidade mediadas pelas tics

de Ezequiel Redin, Paulo Roberto Cardoso da Silveira, Gisele Martins Guimarães e Vilson

Flores dos Santos

Nesse interim, reconhece-se que o avanço das TICs no meio rural vem fornecendo novas dinâmicas em relação à comunicação e a sociabilidade, promovendo simbioses na juventude rural, aqui compreendida como uma construção social, como sugere Bourdieu (1984: 152), quando diz que “(...) a juventude e a velhice não são dadas, mas construídas socialmente, na luta entre jovens e velhos. A relação entre idade social e idade biológica são muito complexas" e cujas ações estão ancoradas no sujeito coletivo, diante das esferas do circuito social em que se estabelecem e legitimam enquanto gerações juvenis.

A juventude rural é analisada no campo teórico como sujeito de transformação do campo (CASTRO, 2005), como grupo responsável pela sucessão ou êxodo rural (DIRVEN, 2001), como agentes da manutenção e preservação do patrimônio da família rural através das estratégias matrimoniais e reprodução biológica (BOURDIEU, 2009), como ator político (STROPASOLAS, 2006, CASTRO, 2009), como agentes promotores de espaços sociais ligados ao lazer, convívio, entretenimento e troca de experiências (REDIN e SILVEIRA, 2012).

A juventude nas sociedades camponesas, geralmente, coincide com uma etapa de semidependência social, assinalada por uma precoce inserção produtiva e por um status subordinado dos jovens no seio da família. Apesar da subordinação doméstica, em que não possuem prestígio e poder, ocupam lugar central no espaço lúdico no âmbito da comunidade e, frequentemente, participam em muitos aspectos da vida festiva, institucionalizada, mediante agrupamentos coletivos (FEIXA PÀMPOIS, 2004), como os grupos de jovens rurais unificados na Associação Regional da Juventude Rural no Território Centro Serra, RS, objeto deste estudo.

Estudos como de Champagne (1986) alertam para a ampliação do espaço social dos jovens rurais e a redução de controle da família camponesa. O isolamento geográfico e social do meio rural tradicional tem efeitos sobre a sociabilização dos jovens. A partir do caso da zonas de bosques, o autor mostra que a dispersão do habitat e a relativa autonomia econômica reforçavam o isolamento das famílias rurais e lhes davam um monopólio de fato na socialização de seus filhos, favorecendo assim uma reprodução social estritamente ligada a sua concepção de mundo, uma transcrição análoga. Tal fato proporcionava que as famílias rurais conseguissem controlar rigidamente todos os seus membros ao longo do tempo, sem concorrência (CHAMPAGNE, 1986). 
Juventude rural e novas formas de sociabilidade mediadas pelas tics

de Ezequiel Redin, Paulo Roberto Cardoso da Silveira, Gisele Martins Guimarães e Vilson

Flores dos Santos

Em contexto contemporâneo, especificamente na realidade sul-brasileira, o avanço das TICs para o meio rural, a expansão e interiorização das universidades e institutos federais de educação técnica e superior tem colocado em xeque o saber da família e o controle mais rígido do jovem no meio rural. Esse fenômeno provoca um empoderamento do jovem perante a família e, em certa medida, uma ampliação das opções em relação ao seu futuro profissional, o que certamente pode favorecer os processos migratórios.

Portanto, conforme Champagne (1986), naquele espaço de interconhecimento onde tudo se sabia, as famílias podiam envolver total e continuamente a vida de seus filhos, vigiando suas atividades e suas amizades e controlando, até mesmo induzindo, os casamentos. Desse modo, impunham seus valores, seu estilo de vida e sua acepção de excelência profissional. Nesse contexto de microssociedade, acontecia a sucessão porque isso era evidente, seja por dever ou por obrigação familiar (CHAMPAGNE, 1986) e também pelas reduzidas opções que se colocavam como viáveis diante da incerteza do abandono da vida na aldeia. A sociedade global se mostrava hostil e o estranhamento dos jovens, diante das vivências possíveis fora da aldeia, os atemorizava e acuava.

Mesmo assim, no contexto do sul do Brasil, a partir da década de 1940-1950, as famílias de agricultores veem no estudo uma possibilidade para que os filhos consigam trabalho no meio urbano, considerando a saída do rural como sinônimo de acesso a melhores condições de vida (SILVEIRA, 1994). Segundo investigação conduzida pelo grupo de pesquisa "Sociedade, Ambiente e Desenvolvimento Rural" da Universidade Federal de Santa Maria (WWW.ufsm.br/desenvolvimentorral), nos anos de 1990 a 1994, demonstra-se que o trabalho agrícola é visto como sacrifício e, principalmente as mulheres são estimuladas a migrarem, já que os filhos homens representavam potencial de mão-de-obra capaz de definir a capacidade de reprodução social da família. Neste contexto, deve-se considerar também a prática comum no Sul do Brasil, de famílias adquirirem área em regiões de novas fronteiras agrícolas em estabelecimento e com isto viabilizar a migração de parte da família (ou até de famílias inteiras), buscando manter-se na agricultura.

Deve-se salientar o papel que a educação tem cumprido neste processo de desvalorizar a vida rural, enquanto reforça a ideia de que o espaço urbano oferece mais atrativos, tanto em trabalho, quanto em qualidade dos serviços públicos disponíveis. Hoje, verifica-se um movimento em defesa de uma educação voltada a realidade rural e que busque despertar nos 
Juventude rural e novas formas de sociabilidade mediadas pelas tics

de Ezequiel Redin, Paulo Roberto Cardoso da Silveira, Gisele Martins Guimarães e Vilson

Flores dos Santos

jovens expectativas em relação ao rural e crie perspectivas de renda e de um modo de vida no campo.

Este contexto muda radicalmente quando a crise econômica que se instala no Brasil, na década de 1980, provoca diminuição da oferta de empregos urbanos de maior remuneração, enquanto os problemas da hipertrofia urbana passam a ser sentidos de forma mais precisa. Assim, a atração pelo meio urbano se arrefece e, em algumas regiões, é o trabalho em tempo parcial que guia as estratégias de reprodução social (mantendo a família toda no campo, mas com alguns membros se assalariando em parte ou na integralidade no meio urbano). Este processo assume muito mais força nas regiões mais próximas dos grandes e médios centros urbanos, onde a disponibilidade de empregos é maior.

Ao mesmo tempo, na virada do século, muda-se a situação vivenciada no rural com o acesso as TICS. O jovem rural quando dispõe destas coloca-se frente a um leque de possibilidades de interação que segundo Belloni (2001), significa a ação recíproca entre dois ou mais atores onde ocorre a intersubjetividade.

Neste esforço investigativo, busca-se analisar o impacto nas relações sociais locais e sobre a projeção futura da vida dos jovens no espaço rural. Deste modo, pode-se perceber a transformação na perspectiva em relação à sucessão rural e novos aportes a serem utilizados como ferramentas de consolidação da organização dos jovens rurais, tendo como consequência iniciativas de formação com uso da educação a distância, a maior circulação de informações e as possibilidades de motivação para a ação coletiva.

Toma-se como referência o conceito de campo de Bourdieu, o qual permite compreender a teia de relações construídas no processo de organização, onde através de saberes compartilhados no processo coletivo de ação política, define-se uma identidade coletiva. Metodologicamente, realizamos dois movimentos de investigação: resgata-se o processo organizativo da AREJUR, conhecendo seus códigos em relação às perspectivas político-culturais enquanto jovens rurais, avançando-se desta forma para o conhecimento do processo de constituição de um campo em torno da juventude rural como ator social coletivo, o qual se articula em torno de suas demandas/expectativas e de um conjunto de relações institucionais. Em outro momento, dirige-se o olhar para as transformações que perpassam o rural com a vivência no uso das TICs.

Este trabalho deriva de vários estudos que vem sendo realizados na Região Centro Serra, RS, aqui sistematizados em função da transformação das formas de sociabilidade da 
Juventude rural e novas formas de sociabilidade mediadas pelas tics

de Ezequiel Redin, Paulo Roberto Cardoso da Silveira, Gisele Martins Guimarães e Vilson

Flores dos Santos

Juventude Rural enquanto ator coletivo. Visando compreender a relação entre a mudança no rural pela difusão das TICs, a forma como estas interferem na sociabilidade da Juventude Rural, desenvolveu-se oficinas com as doze associações constituintes da AREJUR, colhendose as demandas/expectativas de cada grupo; após, foi utilizado a técnica dos grupos focais, onde os jovens puderam debater seu lugar na sociedade e suas perspectivas futuras como agentes sociais e políticos, enfatizando-se a questão da permanência no rural e a sucessão familiar rural. Nestes momentos, os jovens foram estimulados a agirem como moderadores e, em grupo, foram desafiados a construir conhecimentos. Os resultados desta etapa foram apresentados em um encontro realizado no município de Sobradinho/RS, polo microrregional, em julho de 2013, contando com a presença de representantes de todos os seguimentos de jovens da região, prefeitos e extensionistas rurais.

\section{CONTEXTUALIZANDO A REFERÊNCIA EMPÍRICA: A ASSOCIAÇÃO REGIONAL DA JUVENTUDE RURAL (AREJUR) NA REGIÃO CENTRO SERRA, RIO GRANDE DO SUL}

A Associação Regional de Juventude Rural (AREJUR) foi fundada em três de maio de 2005, constituindo uma entidade educacional, social, cultural e esportiva com tempo indeterminado de duração, de fins não econômicos. Permanentemente, tem como sede o município de Candelária, Rio Grande do Sul, podendo atuar em todos os municípios que exista organização de Conselho ou Associação Municipal de jovens rurais filiados à entidade. Segundo seu estatuto, a AREJUR tem como principais objetivos: a) ser um órgão representativo dos conselhos e associações filiadas; b) assessorar os conselhos e associações municipais filiadas; c) participar e apoiar os eventos dos conselhos e associações municipais filiadas; d) divulgar os trabalhos realizados em prol da juventude rural em âmbito municipal, regional e estadual nos meios de comunicação; e) buscar o patrocínio para a realização de atividades sócio-educativas, tais como: excursões, encontros, convenções, exposições, intercâmbios, seminários, desfiles, treinamentos de lideranças, atividades esportivas, culturais, etc.

A formação da associação regional insere no processo de organização social dos jovens rurais, além da organização de eventos, aspectos legais e de legitimidade social, constituindo um campo simbólico que valoriza as origens, os valores e a força do segmento 
Juventude rural e novas formas de sociabilidade mediadas pelas tics

de Ezequiel Redin, Paulo Roberto Cardoso da Silveira, Gisele Martins Guimarães e Vilson

Flores dos Santos

rural na região que tem a economia primária como motriz. A organização desses grupos indica, segundo estudo realizado sobre a AJURATI por Redin e Silveira (2012), que através das alternativas de lazer, aprendizado e valorização na sociedade, constroem uma visão diferenciada da categoria perante a sociedade urbana, principalmente, e alcançam um espaço representativo e legitimado nos diferentes ambientes de deliberação, conjuntamente com as demais organizações sociais.

A organização regional define prioritariamente o público que ela abrange, tratando de que "os conselhos ou associações municipais de jovens filiados a AREJUR deverão ser formados de filhos de agricultores, ou que tenham vínculo com a atividade rural" (AREJUR, 2005: 03). As entidades sociais de jovens rurais tem conseguido trabalhar no sentido de concretizar, conforme salienta Redin (2012: 136), "graus de sociabilidade, reconhecimento, laços de confiança e respeito na comunidade, ao longo do tempo". Essa condição torna-se mais legitimada com o avanço das tecnologias de informação e comunicação no meio rural e os instrumentos digitais como as redes sociais, além das mídias primárias, secundárias e terciárias. Deste modo, percebe-se que as TICs influenciam no processo de re-organização dos jovens rurais, implicando em agilidade nas tomadas de decisão e aprofundando a integração entre as diferentes células constituintes da AREJUR, ao mesmo tempo, que redimensiona a forma de interação com os extensionistas rurais (tradicionais mediadores entre a "modernidade urbana" e o "atrasado rural").

\section{NOVOS ESPAÇOS DE SOCIABILIDADE DA JUVENTUDE RURAL - EXPECTATIVAS E SONHOS VERSUS PRIORIDADES E AÇÕES}

Descarta-se de início a hipótese de que as novas TICs (computador e internet) impactam, em primeira instância, nos aspectos relativos ao aumento de produção e produtividade em função do acesso a informações em tempo real pelos jovens rurais, excetuando propriedades familiares altamente tecnificadas. A internet no espaço rural é uma possibilidade de ampliação ou criação de novos espaços sociais, portanto, não se cogita no curto prazo associar seu uso ao processo de qualificação do sujeito à prática ou melhorias dos aspectos produtivos. Neste sentido, considera-se que a recente propulsão do capitalismo tem conduzido a, como afirma Sorj (2003: 37): "vários autores a um determinismo tecnológico, à glamourização da internet e a uma visão irrealista das condições sociais dentro das quais a 
Juventude rural e novas formas de sociabilidade mediadas pelas tics

de Ezequiel Redin, Paulo Roberto Cardoso da Silveira, Gisele Martins Guimarães e Vilson

Flores dos Santos

temática funciona e impacta nas pessoas". Tal aparato pode tornar-se futuramente um investimento necessário para potencializar o capital humano e social dos jovens e de agricultores familiares, mas para tanto é imprescindível mobilizar recursos e serviços relativos ao seu aperfeiçoamento, ligados diretamente aos anseios dos jovens como apontam seus sonhos como a possibilidade de ter na região ensino agrotécnico e cursos superiores voltados à vida rural. Nessa alusão, as TICs podem cumprir papel fundamental na melhoria do conhecimento técnico e produtivo, na gestão da propriedade e dos recursos naturais.

Em nível de organização de jovens, as TICs ainda não foram exploradas suficientemente. A expansão da internet na Região Centro Serra tem sido estimulada, especialmente, por empresas de caráter familiar com destaque para àqueles empreendimentos de Arroio do Tigre. Neste município, segundo informação disponibilizada pela Interativa Informática (que atualmente detém aproximadamente 95\% dos usuários de internet no rural do município e boa parte do rural de outros municípios da Região Centro Serra), $45 \%$ dos usuários são famílias agricultoras (internet via rádio), segundo dados de julho de 2012. Isso demonstra que, possivelmente, apresenta-se uma reconfiguração nas relações sociais nas sociedades rurais. As famílias agricultoras estão, aos poucos, aumentando suas interações com o mundo virtual, sendo que um dos principais motivos da família adquirir o serviço refere-se ao estímulo dos filhos.

Em certos locais da Região Centro Serra, os jovens rurais já têm acesso à internet via rádio, o que facilitou suas vidas, ou aproximou-os dos espaços sociais. No entanto, em certa medida, esse processo pode atribuir uma vontade intrínseca de sair do rural, pela percepção fascinante e idealizada do urbano. As diferenças de estilo de vida e as aparentes desigualdades entre o rural e urbano provocam uma insatisfação dos jovens rurais com as pertinentes desigualdades visualizadas, sempre em uma comparação com aqueles de classe média e alta, quase nunca fazendo analogia aos jovens periurbanos (REDIN, 2012).

No interior de Arroio do Tigre, Redin (2011) observou várias famílias com um, dois ou mais celulares, bem como, em menor expressão (mas já bastante visível), computadores, internet via rádio e televisões a cabo; também se visualizou famílias de agricultores com acesso a informações em tempo real sobre o comportamento do clima durante a semana, sobre as projeções para a safra, sobre o comportamento do mercado agropecuário, do dólar, ou informações ligadas ao lazer e ao entretenimento. Em muitos casos, conforme Redin (2011) a motivação para os agricultores adquirirem computadores ligados à internet é explicada pelos 
Juventude rural e novas formas de sociabilidade mediadas pelas tics

de Ezequiel Redin, Paulo Roberto Cardoso da Silveira, Gisele Martins Guimarães e Vilson

Flores dos Santos

seguintes elementos: a) pela presença de investidores privados na cidade de Arroio do Tigre, o que demonstra que visualizaram oportunidade de mercado; b) pela existência de jovens, na propriedade, que necessitam elaborar trabalhos pelo computador, para fins de estudos no ensino médio, sendo muito custoso o deslocamento destes à cidade; ou, talvez o mais importante, c) o agricultor adquire a tecnologia e os serviços de internet com o objetivo de motivar a permanência do jovem rural na propriedade (REDIN, 2011). Esse último elemento é um fator relevante, uma vez que os jovens são os únicos que sabem manusear o equipamento, sendo que alguns agricultores aprendem com os filhos. Ao mesmo tempo, esse processo acelera a inclusão digital dos agricultores (REDIN, 2011).

A pesquisa de campo revelou que as TICs mantem relação direta com as expectativas e as prioridades estabelecidas pela juventude rural em âmbito de região. No campo das expectativas foram citadas, especialmente, a criação de uma escola técnica na região para qualificação dos jovens rurais, a construção de projetos e políticas específicas para atender as demandas levantadas pelos diferentes grupos de jovens e a melhoria nas condições de comunicação, envolvendo acesso a internet e telefonia rural. Diante da voz dos jovens, foram reivindicados maiores investimentos destinados a empreendimentos gestados por jovens rurais (Quadro 1). O espaço de construção de planejamento dessas ações prioritárias está guiado, no momento, pela universidade e instituições parcerias como a Empresa de Assistência Técnica e Extensão Rural (EMATER/RS).

Quadro 1 - Expectativas e prioridades dos jovens rurais vinculados a AREJUR Fonte: Pesquisa de campo 2013, elaborado pelos autores.

\begin{tabular}{|l|l|l|}
\hline $\begin{array}{l}\text { AREJUR/ } \\
\text { Atributos de análise }\end{array}$ & \multicolumn{1}{|c|}{$\begin{array}{c}\text { Expectativas e sonhos da Juventude } \\
\text { Rural }\end{array}$} & $\begin{array}{l}\text { Ações/Prioridades em âmbito local/ } \\
\text { regional }\end{array}$ \\
\hline \multirow{5}{*}{ AJURATI } & $\begin{array}{l}\text { 1) ser bem sucedido; 2) que as tecnologias } \\
\text { cheguem ao meio rural; 3) melhor } \\
\text { qualificação para os jovens rurais; 4) } \\
\text { aumentar a diversificação de cultivos e } \\
\text { atividades; 5) ampliar o mercado para } \\
\text { produtos da agricultura familiar; 6) maior } \\
\text { remuneração da produção. }\end{array}$ & $\begin{array}{l}\text { 1) disponibilizar acesso a internet nas } \\
\text { comunidades rurais; 2) implantação de } \\
\text { uma Escola técnica; 3) projetos de } \\
\text { diversificação desenvolvidos pelas } \\
\text { prefeituras municipais; 4) proporcionar } \\
\text { condições para o escoamento da } \\
\text { produção; 5) elevar os investimentos no } \\
\text { esporte. }\end{array}$ \\
\hline \multirow{5}{*}{ AJUREV } & $\begin{array}{l}\text { 1) Escola técnica } \\
\text { 1) incentivo a bacia leiteira; 2) } \\
\text { incentivo a atividades agrícolas }\end{array}$ \\
\hline \multirow{2}{*}{ AJURI } & $\begin{array}{l}\text { 1) ter um planejamento em âmbito regional } \\
\text { que traga benefícios para a agricultura } \\
\text { familiar; 2) formação de Conselho } \\
\text { Regional que fortaleça a agricultura; 3) } \\
\text { Colégio Agrícola Regional; 4) criação de }\end{array}$ & $\begin{array}{l}\text { 1) garantia de mercado dos produtos da } \\
\text { agricultura familiar, como forma de } \\
\text { gerar renda e permanência do jovem no } \\
\text { meio rural; } \\
\text { incentivo a projetos voltados a }\end{array}$ \\
\hline
\end{tabular}


Juventude rural e novas formas de sociabilidade mediadas pelas tics

de Ezequiel Redin, Paulo Roberto Cardoso da Silveira, Gisele Martins Guimarães e Vilson

\begin{tabular}{|c|c|c|}
\hline & $\begin{array}{l}\text { uma agroindústria que atinja os doze } \\
\text { municípios para que haja fortalecimento } \\
\text { em meio aos produtores rurais. }\end{array}$ & $\begin{array}{l}\text { agricultura; } \\
\text { liberação de verbas para o } \\
\text { fortalecimento da Associação } \\
\text { Municipal em suas ações. }\end{array}$ \\
\hline $\begin{array}{l}\text { ASSOCIAÇÃO DE } \\
\text { JUVENTUDE } \\
\text { RURAL DE } \\
\text { JACUIZINHO }\end{array}$ & $\begin{array}{l}\text { 1) melhorar as condições com } \\
\text { financiamentos, recursos para os jovens } \\
\text { permanecer no meio rural; 2) incentivos e } \\
\text { apoio do poder público; 3) valorização do } \\
\text { produto produzido por nós; 4) buscar } \\
\text { crédito para investirem nas propriedades; } \\
\text { 5) incentivo a implantação de novas } \\
\text { tecnologias; 6) incentivo para a } \\
\text { comercialização de produtos agrícolas; 7) } \\
\text { investimento em piscicultura, avicultura, } \\
\text { suinocultura e apicultura para os jovens; 8) } \\
\text { investir mais na patrulha agrícola; 9) } \\
\text { aproveitar os Polos UAB existentes } \\
\text { Jacuizinho e Sobradinho; 10) buscar em } \\
\text { conjunto com a região, Universidades e } \\
\text { Institutos Federais (cursos } \\
\text { profissionalizantes e de Graduação } \\
\text { voltados ao meio rural). }\end{array}$ & $\begin{array}{l}\text { 1) falta de tecnologia no campo; 2) } \\
\text { incentivo agrícola e programas voltados } \\
\text { à agricultura familiar; 3) acesso a terra; } \\
\text { 4) falta de investimento diretamente ao } \\
\text { jovem; 5) falta de transporte/locomoção } \\
\text { para os jovens estudar; 6) apoio para o } \\
\text { jovem permanecer no campo }\end{array}$ \\
\hline AJURLABS & $\begin{array}{l}\text { 1) fortalecer as atividades da AREJUR, } \\
\text { motivando os Jovens a participarem dos } \\
\text { grupos; }\end{array}$ & $\begin{array}{l}\text { 1) acesso asfáltico; 2) oportunidade de } \\
\text { emprego; 3) desenvolvimento social; 4) } \\
\text { mais acesso ás tecnologias;5) apoio de } \\
\text { órgãos públicos; 6) desenvolvimento da } \\
\text { Associação de Juventude Rural }\end{array}$ \\
\hline AJURAL & & $\begin{array}{l}\text { 1) melhorar o acesso as políticas } \\
\text { públicas; 2) acesso à internet e } \\
\text { telefonia; 3) melhorar a infraestrutura } \\
\text { das comunidades; 4) acesso asfáltico; 5) } \\
\text { Escola Técnica Agrícola regional }\end{array}$ \\
\hline AMJURPS & $\begin{array}{l}\text { 1) cursos de capacitação e incentivo a } \\
\text { permanência do jovem no meio rural; 2) } \\
\text { políticas públicas, voltadas exclusivamente } \\
\text { aos jovens; 3) apoio financeiro as } \\
\text { lideranças dos jovens que buscam } \\
\text { conhecimentos; 4) melhorar as estradas e o } \\
\text { transporte nas localidades que tem difícil } \\
\text { acesso; 5) divulgação dos eventos } \\
\text { promovidos pelos jovens; 6) apoio do } \\
\text { poder municipal para as atividades } \\
\text { recreativas e culturais; 7) inclusão de } \\
\text { recursos aos jovens no plano plurianual do } \\
\text { município; 8) sinal de telefonia e internet, } \\
\text { disponível em todo o interior do } \\
\text { município; 9) cursos de liderança para os } \\
\text { representantes dos grupos de jovens; 10) } \\
\text { apoio e busca por um instituto federal } \\
\text { (escola técnica) para o Centro Serra; } 11 \text { ) }\end{array}$ & $\begin{array}{l}\text { 1) criação de projetos pelo poder } \\
\text { legislativo e executivo de apoio } \\
\text { financeiro para os jovens realizarem } \\
\text { atividades culturais, sociais, recreativas } \\
\text { e de desenvolvimento rural, } \\
\text { incentivando a sucessão familiar e as } \\
\text { alternativas de desenvolvimento rural. }\end{array}$ \\
\hline
\end{tabular}




\begin{tabular}{|c|c|c|}
\hline & $\begin{array}{l}\text { integração entre os municípios na busca de } \\
\text { apoio aos jovens; 12) construção de um } \\
\text { hospital público no Centro Serra; 13) } \\
\text { apoio das lideranças estaduais e federais a } \\
\text { nível regional nas atividades da juventude } \\
\text { rural; 14) políticas públicas a nível de } \\
\text { estado aos jovens }\end{array}$ & \\
\hline AJURS & & $\begin{array}{l}\text { 1) acesso a internet no interior; 2) } \\
\text { Criação de Lei Municipal de Incentivo a } \\
\text { Juventude Rural; 3) valorização da } \\
\text { Juventude Rural; 4) Escola Técnica } \\
\text { Profissionalizante; 5) implantação de } \\
\text { projetos voltados a Juventude; 6) } \\
\text { comprometimento dos políticos; }\end{array}$ \\
\hline CODEJURS & & $\begin{array}{l}\text { 1) melhorar qualidade de vida no meio } \\
\text { rural; 2) produzir alimentos mais } \\
\text { saudáveis; 3) promover a formação de } \\
\text { lideranças; 4) promover o acesso a } \\
\text { informação - internet e demais meios de } \\
\text { comunicação; 5) acesso ao crédito; } 6 \text { ) } \\
\text { acesso a terra; 7) cursos de formação } \\
\text { profissional com acesso diferenciado } \\
\text { em instituições públicas. }\end{array}$ \\
\hline AMJURS & & $\begin{array}{l}\text { 1) criação de um Centro Esportivo; 2) } \\
\text { incentivo as agroindústrias; 3) maior } \\
\text { apoio financeiro do Poder Executivo; 4) } \\
\text { Palestras, seminários e cursos de } \\
\text { capacitação em diversas áreas; 5) } \\
\text { criação da Secretária de esportes; 6) } \\
\text { melhoria do sinal de internet e telefonia } \\
\text { móvel no meio rural;7) Escola Técnica; } \\
\text { 8) Trazer agroindústrias para a região; } \\
\text { 9) Palestras, seminários e cursos de } \\
\text { capacitação em diversas áreas; 10) } \\
\text { melhoria do sinal de internet e telefonia } \\
\text { móvel no meio rural;11) acesso } \\
\text { asfáltico intermunicipais; 12) busca de } \\
\text { recursos a nível de Arejur para repassar } \\
\text { em forma de subvenção as juventudes } \\
\text { integrantes para utilizarem em suas } \\
\text { olimpíadas. }\end{array}$ \\
\hline
\end{tabular}

A experiência da AREJUR tem demonstrado que o processo de organização da Juventude Rural faz dos jovens importantes atores no cenário político, sendo muitos os que passam a ocupar funções públicas (vereadores, secretários, membros de consórcios intermunicipais) e funções de liderança (presidência de sindicatos, associações e cooperativas). Neste processo de organização, constroem expectativas de poder interferir nas 
Juventude rural e novas formas de sociabilidade mediadas pelas tics

de Ezequiel Redin, Paulo Roberto Cardoso da Silveira, Gisele Martins Guimarães e Vilson

Flores dos Santos

políticas públicas e nas decisões sobre o desenvolvimento de suas comunidades. Assim, com base no quadro citado anteriormente, percebe-se estas expectativas, as quais em conjunto representam elementos de um processo de construção identitária, o qual coloca a Juventude Rural com uma perspectiva de ver o rural, revalorizando suas potencialidades e redefinindo seu sentido. Percebe-se a emergência de outro universo simbólico, para o qual assume relevância as TICs.

O avanço do computador, dada sua popularização e acessibilidade, além da adesão dos serviços de internet pelas famílias rurais inseriram uma nova forma de sociabilização entre os usuários. Os jovens rurais conectam-se a outros jovens, trocam contatos, combinam dias de lazer, encontro e jogos esportivos. Através das redes sociais, especialmente, informam-se de fatos cotidianos, recebem informações da comunidade local e até de noticiários em termos mais amplos e globais (nacional e mundial). Compartilham e recebem informações, inserem sua visão de mundo e estão expostos a contrapontos. Dessa forma, passam de sujeitos ocultos (off-line) a sujeitos visíveis (online) no mundo virtual. A priori não produzem informação, mas compartilham conteúdos que teoricamente concordam ou que, em certa medida, estejam coerentes com sua percepção de mundo.

As redes sociais convocam os jovens a organizarem-se em forma de grupos para compartilharem informações sobre a Juventude Rural. As informações coletivas geralmente estão ligadas aos encontros esportivos e eventos sociais que participam em âmbito de município ou fora deste. Além disso, a rede social serve como forma de convocação para participação de espaços deliberativos entre os grupos de jovens, seja a nível local, municipal ou regional.

A criação de perfis sobre as entidades representativas nas redes sociais (como exemplo, a AJURATI) tratam de legitimar socialmente a ação dos jovens rurais, ações que acontecem no espaço público e transcendem para a rede virtual. As participações da juventude rural em festivais artísticos e culturais, eventos esportivos, espaços deliberativos sobre ações de intervenção local/regional, organização de eventos sociais, participação em ações alusivas à cultura e as convenções sociais do território podem ser encontradas principalmente nas redes sociais, e também nos sites de notícias regionais (rádios, jornal, e portais virtuais do território). Essas informações que ocorrem localmente e podem ser acompanhadas por jovens que saíram da região, mas que privilegiam acompanhar os acontecimentos em nível local, fenômeno fortalecido pelo vínculo afetivo e sua raiz cultural. Do mesmo modo, as novas TICs 
Juventude rural e novas formas de sociabilidade mediadas pelas tics

de Ezequiel Redin, Paulo Roberto Cardoso da Silveira, Gisele Martins Guimarães e Vilson

Flores dos Santos

proporcionam o contato mais próximo entre os jovens rurais e os meios de comunicação local, em especial, as rádios e o jornal impresso (também estabelecido de forma virtual) na Região Centro Serra.

A sociabilidade do jovem rural em interação com diferentes usuários, mediados pela conexão digital, promove no seu imaginário uma relação de autonomia em relação a suas decisões. Essa condição promove conflitos no âmbito de família rural, provocando um diálogo controverso entre o que o grupo doméstico prega como valores a serem seguidos em confronto com as novas concepções dos jovens, diante dessa interação virtual. De outro lado, a ampliação dos espaços sociais e interativos promove uma legitimidade social diante do território. A representação organizativa da Associação da Juventude Rural na Região Centro Serra e suas juventudes associadas com seus respectivos grupos de jovens criam uma rede social que congrega determinados capitais sociais, culturais e simbólicos (BOURDIEU, 2003) angariando um espaço na sociedade regional, fruto de uma imersão legitima do grupo em função do respeito a leis, interagindo com as disputas e se relacionando enquanto classe social no campo (BOURDIEU, 1989).

Os jovens atores organizados, dispostos de instrumentos tecnológicos informacionais, enquanto agentes sociais focam-se principalmente em aspectos relativos à sua sociabilidade gerando espaços de lazer e entretenimento, inserindo-se como agentes passivos em relação a intervenção no desenvolvimento rural local. Diante dessa perspectiva, as lideranças juvenis, dispostas de auxílio dos serviços da extensão rural e de agentes de desenvolvimento, provocam a juventude rural a pensar localmente e regionalmente em relação às ações e prioridades para a intervenção pública. Diante desse aparato, é necessário um impulso externo, um processo de animação social que conduza e mobilize a juventude rural no sentido de torná-los sujeitos interlocutores do local. Diante do aparato tecnológico informacional e da capacidade dos jovens, eles não se sentem legítimos ou não tem interesse em discussões de âmbito geral. Geralmente, pensam ações pontuais e localizadas como uma má estrada ou um serviço público não realizado em sua localidade, os quais julgam de dever municipal.

\section{CONSIDERAÇÕES FINAIS}

As tecnologias de comunicação e informação no meio rural vista de forma isolada, apesar de seus efeitos globalizantes, são incipientes para muni-los de informação a fim de 
Juventude rural e novas formas de sociabilidade mediadas pelas tics

de Ezequiel Redin, Paulo Roberto Cardoso da Silveira, Gisele Martins Guimarães e Vilson

Flores dos Santos

torná-los agentes ativos do desenvolvimento rural. As juventudes rurais atuam camufladas, fornecendo ou passando a responsabilidade aos atores legalmente institucionalizados para tal ação, como a extensão rural local, os vereadores e a prefeitura local, ou seja, a gestão pública como principal ator nesse campo para mudar a realidade rural atual. Por enquanto isentam-se, pois sua ação se legitima enquanto uma entidade que prioriza a sociabilidade.

O avanço das TICs no meio rural potencializa a ativação de recursos humanos, gerando uma transmissão de valores e significados ligados ao ethos camponês. As TICs ainda não atingiram uma escala totalizante no meio rural, mas já se verifica um acentuado avanço de adoção, especialmente, derivado a popularização da tecnologia, o aumento de circulação do capital econômico e as condições geográficas no território em questão. A juventude rural se apropria das TICs em diferentes âmbitos, seja na esfera domiciliar, nas instituições escolares ou empreendimentos privados ligados a área de informática. Grosso modo, em longo prazo, esse fato pode impactar e diferenciar as formas de mobilização e interação da juventude rural, principalmente aquela organizada pela AREJUR. Como se desprende dos dados analisados, é na busca por formação técnica e universitária que a Juventude Rural pode encontrar nas TICs um grande potencial, viabilizando novas formas de construção de conhecimento e de aproximação com instituições de produção de conhecimento, gerando novas sociabilidades e re-construindo seu processo identitário como ator coletivo de transformação da vida rural.

\section{REFERÊNCIAS BIBLIOGRÁFICAS}

AREJUR. Estatuto da Associação Regional da Juventude Rural. Candelária: Registro de Imóveis, 2005.

BELLONI, M. L. Educação a Distância. 2 ed. Campinas: Autores Associados, 2001.

BORDENAVE, J. E. D. O que é comunicação rural. São Paulo: Ed. Brasiliense, 1983.

BOURDIEU, P. O Poder Simbólico. Rio de Janeiro: Editora Bertrand Brasil, 1989.

BOURDIEU, P. O senso prático. Petrópolis, RJ: Vozes, 2009.

BOURDIEU, P. Questions de sociologie. Paris. Éditions de Minuit, 1984.

BOURDIEU, P. Questões de sociologia. 1984. Tradução de Miguel Serras Pereira. Paris: Les Éditions de Minuit, 2003.

CAMARANO, A. A.; ABRAMOVAY, R. Exxodo rural, envelhecimento e masculinização no Brasil: Panorama nos últimos 50 anos. 1997. 
Juventude rural e novas formas de sociabilidade mediadas pelas tics

de Ezequiel Redin, Paulo Roberto Cardoso da Silveira, Gisele Martins Guimarães e Vilson

Flores dos Santos

CAMARANO, A. A.; ABRAMOVAY, R. Exxodo rural, envelhecimento e masculinização no Brasil: panorama dos últimos 50 anos. Rio de Janeiro: IPEA, 1999. 28p. Disponível em: <http://www.dominiopublico.gov.br/download/ texto/td_0621.pdf>. Acesso em: 01 ago. 2012.

CASTRO, E. G. Juventude rural no Brasil: processos de exclusão e a construção de um ator político. Revista Latinoamericana de Ciencias Sociales, Niñez y Juventud. Manizales, v. 7, n. 1, jan. 2009.

CASTRO, E. G. Juventude rural: "apenas uma palavra" ou "mais do que uma palavra". In: XXIX ENCONTRO ANUAL DA ANPOCS. 2005, Caxambu/MG. Anais... Caxambu/MG, 2005: 1-38.

CGI.BR - Comitê Gestor da internet no Brasil - Pesquisa sobre o uso das tecnologias da informação e da comunicação no Brasil: TIC Domicílios e TIC Empresas 2011. São Paulo: CGI.BR, 2012. Disponível em: <http://op.ceptro.br/cgi-bin/cetic/tic-domiciliose-empresas-2011.pdf>. Acesso em 01 de Ago. 2013.

CHAMPAGNE, P. Elargissement de l'espace social et crise de l'identité paysanne. Cahiers d'économie et sociologie rurales, $\mathrm{n}^{\circ}$ 3, décembre 1986: 73-89.

DIRVEN, M. La herencia de tierras y la necesidad de rejuvenecimiento del campo latinoamericano: propuestas preliminares. In: el VI Congreso de Economistas Agrarios de Chile "Gestión de Transferencia Tecnológica en la Agricultura" 29-30 de Novembro de 2001. Anais... Santiago do Chile, 2001.

FEIXA PÀMPOIS, C. A construção histórica da juventude. In: CACCIA-BAVA, A.; FEIXA PÀMPOIS, C.; CANGAS, Y.G. Jovens na América Latina. São Paulo: Escrituras Editora, 2004.

FREIRE, Paulo. Extensão ou Comunicação? Rio de Janeiro: Ed. Paz e Terra, 1977.

GRAZIANO DA SILVA, J. O Novo rural brasileiro. Campinas, IE/UNICAMP, 1999.

REDIN, E. Entre o produzir e o reproduzir na agricultura familiar fumageira de Arroio do Tigre/RS. 262p. Dissertação (Mestrado em Extensão Rural) PPGExR/UFSM, Santa Maria, 2011.

REDIN, E. Jovem rural em questão. Sociais e Humanas. Santa Maria, v. 25, 2012: 123-139

REDIN, E.; SILVEIRA, P. R.C. Juventude rural: experiências e perspectivas. In: SANTOS, V. F.; VELA, H. A. G.; SILVEIRA, P. R. C. Educação rural no mundo contemporâneo. Santa Maria: UFSM, 2012: 175-208 
Juventude rural e novas formas de sociabilidade mediadas pelas tics

de Ezequiel Redin, Paulo Roberto Cardoso da Silveira, Gisele Martins Guimarães e Vilson

Flores dos Santos

SIMMEL, G. Sociologia. Organizador [da coletânea] Evaristo de Moraes Filho; São Paulo: Ática, 1983.

SILVEIRA, P.R.C. Reflexões sobre o modo de gestão em unidades de produção familiares um estudo exploratório. 209 p. Dissertação (Mestrado em Extensão Rural) PPGExR/UFSM, Santa Maria, 1994.

SORJ, B. brasil@povo.com - A Luta contra a desigualdade na sociedade da informação. Rio de Janeiro: Jorge Zahar, 2003.

STROPASOLAS, V. L. O mundo rural no horizonte dos jovens. Florianópolis: Editora da UFSC, 2006.

WEISHEIMER, N. A situação juvenil na agricultura familiar. Tese de Doutorado (Doutorado em Sociologia) UFRGS, Porto Alegre, 2009.

Artigo submetido: 12/09/2013

Artigo aprovado: 18/10/2013 